\title{
SISTEM INFORMASI GEOGRAFIS LOKASI RUMAH PEJABAT POLDA GORONTALO BERBASIS ANDROID
}

\author{
${ }^{1}$ Marlin Lasena, ${ }^{2}$ Ramli Abdul Rahman \\ ${ }^{1,2}$ STMIK Ichsan Gorontalo, Indonesia \\ Imarlinlasena@gmail.com; ${ }^{2}$ miftahbiki@gmail.com;
}

\section{Article Info}

Article history:

Received, 30/08/2021

Revised, 07/09/2021

Accepted, 13/11/2021

\section{Kata Kunci:}

Sistem Informasi Geografis, Rumah Pejabat, Polda Gorontalo, Android

Keywords:

Geographical Information System, Official House, Polda Gorontalo, Android

\begin{abstract}
ABSTRAK
Kepolisian Republik Indonesia adalah salah satu fungsi pemerintahan Negara di bidang pemeliharaan keamanan dan ketertiban masyarakat, penegakan hukum, perlindungan, pengayoman, dan pelayanan kepada masyarakat. Saat ini rumah pejabat Polda Gorontalo mulai dari pejabat Polda, Polres dan Polsek dalam wilayah Provinsi Gorontalo belum dilakukan pendataan. Hal ini dikarenakan kebutuhan akan informasi alamat rumah pejabat Polda Gorontalo sangat dibutuhkan oleh aparat kepolisian terutama untuk memudahkan dalam hal koordinasi dan administrasi. Untuk mengatasi hal tersebut akan dibuatkan sebuah sistem informasi geografis yang berbasis android agar dapat menyelesaikan permasalahan yang terjadi selama ini serta memudahkan akses untuk mengetahui lokasi rumah pejabat Polda Gorontalo sehingga proses pendataan yang dilakukan oleh polda lebih efektif dan efisien. Hasil penelitian ini nantinya akan di implementasikan di Polda Gorontalo dengan maksud untuk memudahkan aparat kepolisian dalam mencari lokasi dan mendapatkan informasi tentang daftar pejabat dan history pejabat. Dengan pemanfaatan teknologi ini, pengguna akan lebih cepat dan akurat untuk mendapatkan lokasi rumah pejabat Polda Gorontalo.

\section{ABSTRACT}

The Police of the Republic of Indonesia is one of the functions of the State government in the field of maintaining security and public order, law enforcement, protection, shelter, and service to the community. Currently, the houses of Gorontalo Regional Police officials, starting from Polda, Resort Police and Sector Police officers in the Gorontalo Province area, have not yet been collected. This is because the need for information on the home address of Gorontalo Regional Police officials is very much needed by the police, especially to facilitate coordination and administration. To overcome this, an Android-based geographic information system will be created in order to solve the problems that have occurred so far and facilitate access to find out the location of the Gorontalo Regional Police official's house so that the data collection process carried out by the Regional Police is more effective and efficient.The results of this study will later be implemented at the Gorontalo Regional Police with the aim of making it easier for police officers to find locations and obtain information about official lists and official history. With the use of this technology, users will be faster and more accurate in getting the home location of Gorontalo Regional Police officials.
\end{abstract}

This is an open access article under the CC BY-SAlicense.

Penulis Korespondensi:

Marlin Lasena,

Program Studi Sistem Informasi,

STMIK Ichsan Gorontalo

Email: marlinlasena@gmail.com

\section{PENDAHULUAN}

Sistem informasi Geografis adalah bagian yang terdiri dari Hardware, software, informasi geografis, dan SDM yang bekerja sama secara memadai untuk memasukkan, menyimpan, meningkatkan, memperbarui, mengawasi, mengontrol, mengoordinasikan, dan menampilkan informasi dalam suatu kerangka data. berbasis geografis [1]. Aplikasi sistem informasi geografis saat ini berkembang tidak hanya dalam hal jumlah penggunaan tetapi juga dalam hal berbagai penggunaan. Penyempurnaan aplikasi SIG nantinya memunculkan aplikasi berbasis android. 
Kepolisian Republik Indonesia (Polri) adalah salah satu fungsi pemerintahan Negara di bidang pemeliharaan keamanan dan ketertiban masyarakat, penegakan hukum, perlindungan, pengayoman, dan pelayanan kepada masyarakat [2]. Berdasarkan keorganisasian Polri tingkat pusat disebut Markas Besar Kepolisian Negara Republik Indonesia (Mabes Polri), sedang organisasi Polri tingkat kewilayahan disebut Kepolisian Negara Republik Indonesia Daerah (Polda) di tingkat provinsi, Kepolisian Negara Republik Indonesia Resort (Polres) di tingkat kabupaten/kota, dan Kepolisian Negara Republik Indonesia Sektor (Polsek) di tingkat kecamatan. Kepolisian Daerah Gorontalo atau Polda Gorontalo adalah pelaksana tugas Kepolisian Republik Indonesia di wilayah Provinsi Gorontalo. Polda Gorontalo karena tergolong Polda tipe A [3].

Pejabat Polri yang ada di Provinsi Gorontalo berupa Pejabat Polda, Polres, dan Polsek. Para pejabat tersebut mendapatkan fasilitas rumah dari pemerintah, akan tetapi adapun beberapa pejabat yang memiliki rumah sendiri. Hal ini menyebabkan aparat maupun admin polda yang tidak mengetahui lokasi rumah pejabat-pejabat tersebut, dikarenakan belum ada nya pendaataan. Kebutuhan akan informasi alamat rumah pejabat Polda tersebut sangat dibutuhkan aparat kepolisian terutama untuk memudahkan dalam hal koordinasi dan administrasi. Dalam penelitian ini permasalahan yang ada adalah belum ada sistem informasi mengenai lokasi alamat rumah pejabat Polda Gorontalo dalam bentuk peta digital.

Berdasarkan hal tersebut, munculah inovasi untuk membuat aplikasi sistem informasi geografis yang berbasis android. Hal ini agar dapat memberikan informasi mengenai rumah pejabat Polda Gorontalo dalam bentuk peta digital yang dapat digunakan oleh aparat kepolisian secara mudah. Sistem informasi tersebut digunakan untuk menampilkan data dan memberikan kemudahan dalam penyajian serta pencarian informasi tentang rumah pejabat Polda Gorontalo.

Penelitian ini nantinya akan di implementasikan di Polda Gorontalo dengan tujuan untuk memudahkan pihak admin mendata informasi lokasi rumah pejabat, informasi history pejabat dan informasi lainnya yang dibutukan oleh aparat maupun admin Polda Gorontalo.

\section{A. Sistem Informasi Geografis}

Sistem Informasi Geografis merupakan sistem berbasis komputer yang digunakan untuk menyimpan dan memanipulasi informasi geografis. Sistem informasi geografi diciptakan untuk mengumpulkan, menyimpan dan menganalisis obyek atau fenomena dimana lokasi geografis menjadi karakteristik atau kritik penting untuk analisi. Sistem informasi geografi adalah sistem berbasis komputer yang memiliki kemampuan dalam menangani data berefrensi dalam: (a) masukkan data, (b) manajemen data (penyimpanan dan pemanggilan data), (c) manipulasi dan analisis, (d) keluaran. Pada awalnya, data geografi hanya disajikan di ataas peta dengan menggunakan simbol, garis, dan warna. Elemen-elemen geometri ini dideskripsikan didalam legenda-nya misalnya, garis hitam tebal untuk jalan utama, garis hitam tipis untuk jalan sekunder dan jalan - jalan yang berikutnya. Selain itu, berbagai data juga di dapat dioverlay-kan berdasarkan sistem koordinat yang sama. Akibatnya, sebuah peta menjadi media yang efektif baik sebagai alat presentasi mapun sebagai bank tempat penyimpanan data geografis. Tetapi, media peta masih mengandung kelemahan atau keterbatasan. Tidak mudah untuk mengubah bentuk presentasi ini, sebuah peta selalu menyediakan gambar atau symbol unsur geografi dengan bentuk yang tetap atau statis meskipun diperlukan untuk kebutuhan yang berbeda [4].

Sistem informasi Geografis dapat menyajikan real world (dunia nyata) pada monitor sebagaimana lembaran peta dapat merepresentasikan dunia nyata diatas kertas serta menawarkan peta yangdapat diseret dan gambar satelit untuk seluruh dunia dan menawarkan perencana rute. Tetapi, saat ini Sistem informasi Geografis memiliki kekuatan lebih dan fleksibilitas dari pada lembaran pada kertas. Peta merupakan representasi grafis dari dunia nyata, obyek-obyek yang dipresentasikan di atas peta disebut unsur peta atau map features (contohnya adalah sungai, taman, kebun, jalan dan lain-lain) [5].

SIG sebagai suatu system berbasis komputer yang memiliki kemampuan dalam menangani data bereferensi geografi yaitu pemasukan data, manajemen data (penyimpanan dan pemanggilan kembali), manipulasi dan analisis data, serta keluaran sebagai hasil akhir (output). Hasil akhir (output) dapat dijadikan acuan dalam pengambilan keputusan pada masalah yang berhubungan dengan geografi [1].

SIG adalah sistem yang dapat mendukung pengambilan keputusan spasial dan mampu mengintegrasikan deskripsi-deskripsi lokasi dengan karakteristik-karakteristik fenomena yang ditemukan di lokasi tersebut. SIG yang lengkap mencakup metodologi dan teknologi yang diperlukan yaitu data spasial perangkat keras, perangkat lunak dan struktur organisasi [1].

\section{B. Rumah Pejabat Polda Gorontalo}

Secara umum, rumah dapat diartikan sebagai sebuah tempat di mana penghuninya akan mendapat perlindungan atau tempat bernaung dari segala kondisi alam yang berada di sekitarnya, seperti hujan, panas 
terik matahari, dan sebagainya [6]. Rumah juga merupakan sesuatu yang dijadikan tempat beristirahat penghuninya yang telah melakukan berbagai macam aktivitas di luar yang pembuatannya dibuat berdasarkan pondasi bangunan[6].

Berdasarkan pengertian rumah tersebut maka Rumah Pejabat Polda Gorontalo adalah sesuatu yang dijadikan tempat beristirahat pejabat Polda Gorontalo yang telah melakukan berbagai macam aktivitas di luar yang pembuatannya dibuat berdasarkan pondasi bangunan.

\section{Android}

Android adalah sebuah sistem operasi mobile berbasis linux yang mencakup sistem operasi, middleware, dan aplikasi [7]. Sistem operasi Android bersifat open source sehingga banyak sekali programmer yang membuat aplikasi ataupun memodifikasi sistem operasi Penelitian ini akan di uji coba pada android versi 5.0 (Lollipop). Uji coba program dilakukan di sistem operasi ini karena versi ini telah banyak pembaharuan fitur dan fungsi sistem operasi baik itu dari software dan hardware dari versi - versi sebelumnya. Perbaikan pada sistem operasi versi 5.0 (Lollipop) yaitu peningkatan fungsi input keyboard, desain baru fitur pencarian, pembaharuan fitur voice search, notifikasi bar yang transparan dan beberapa fungsi lainnya. Dengan penggunaan sistem operasi versi 5.0 (Lollipop) dapat menjadikan kinerja aplikasi sistem informasi geografis ini menjadi lebih maksimal. Android. Sampai saat penulisan ini, sistem operasi Android sudah memasuki versi 6.0 [8].

\section{Android SDK (Software Development Kit)}

Android Software Development Kit merupakan alat atau tools yang digunakan untuk membuat aplikasi platform Android dengan bahasa pemrograman java, SDK Android mencakup perangkat pengembangan, emulator, dan libraries yang diperlukan untuk membangun aplikasi Android [9].

\section{E. Web Service}

Web service merupakan aplikasi yang dibuat agar dapat dipanggil atau di akses oleh aplikasi lain melalui internet dengan menggunakan format pertukaran data sebagai format pengiriman pesan [10]. Sebuah web service dipanggil oleh aplikasi lain dengan menggunakan bantuan HTTP (Hypertext Transfer Protocol).

\section{F. Pemrograman Java}

Java bermula dari proyek penelitian perusahaan sun microsystems dengan nama sandi Green pada tahun 1991 [11]. Terdapat prediksi bahwa mikroprosesor akan digunakan luas pada peralatan - peralatan elektronik termasuk smarphone. Karena adanya bermacam - macam tipe mikroprosesor, maka dibutuhkan sebuah bahasa pemrograman yang dapat berjalan di semua mikroprosesor. Melihat peluang ini maka James Gosling, yaitu salah seorang ilmuan komputer yang berperan besar dalam proyek pengembangan bahasa pemrograman java yang dulunya dikenal dengan istilah $O a k$. Nama java di ambil dari salah satu nama jenis kopi dari jawa yang ada pada kedai kopi yang pada waktu itu dikunjungi oleh pegawai dari sun microsystems.

Karena framework android ditulis dengan bahasa pemrograman java, maka untuk dapat merancang aplikasi berbasis android kita wajib untuk mengetahui bahasa pemrograman java terlebih dahulu.

\section{G. Unified Modelling Language (UML)}

Unified Modelling Language (UML) adalah sebuah "bahasa" yg telah menjadi standar dalam industri untuk visualisasi, merancang dan mendokumentasikan sistem piranti lunak. UML menawarkan sebuah standar untuk merancang model sebuah sistem [12]. Dengan menggunakan UML kita dapat membuat model untuk semua jenis aplikasi piranti lunak, dimana aplikasi tersebut dapat berjalan pada piranti keras, sistem operasi dan jaringan apapun, serta ditulis dalam bahasa pemrograman apapun. Tetapi karena UML juga menggunakan class dan operation dalam konsep dasarnya, maka ia lebih cocok untuk penulisan piranti lunak dalam bahasa - bahasa berorientasi objek seperti C++, Java, C\# atau VB.NET. Walaupun demikian, UML tetap dapat digunakan untuk modeling aplikasi prosedural dalam VB atau C.

\section{METODE PENELITIAN}

\subsection{Metode Pengembangan System}

Penelitian ini menggunakan metode Research and Development atau yang dikenal dengan metode Penelitian dan Pengembangan. Metode ini didefinisikan sebagai metode penelitian yang digunakan untuk 
menghasilkan produk tertentu dan menguji keefektifan produk tersebut [9]. Sejalan dengan hal tersebut, Sudaryono mendefinisikan penelitian dan pengembangan sebagai suatu proses pengumpulan dan analisis data dilakukan secara sistematis dan logis untuk mecapai tujuan tertentu [10]. Research and Development membagi metode menjadi 3 bagian dalam penelitian yaitu [9] :

a. Deksriptif. Digunakan dalam studi awal untuk menghimpun data kondisi yang ada yaitu perbandingan kondisi produk yang sudah ada dan yang akan dikembangkan, kondisi pihak pengguna, kondisi faktor pendukung dan penghambat.

b. Evaluatif. Digunakan untuk mengevaluasi proses uji coba pengembangan suatu produk.

c. Eksperimen. Digunakan untuk menguji keampuhan produk yang dihasilkan.

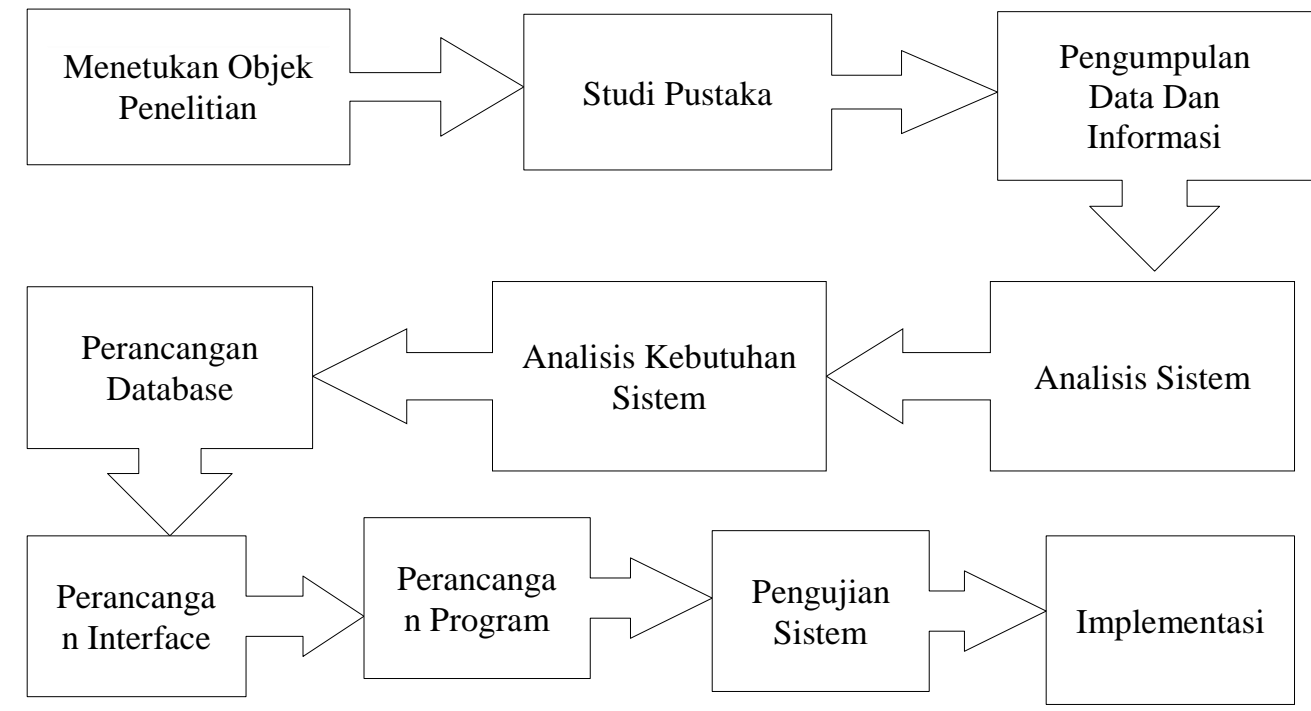

Gambar 1. Tahapan Perancangan Sistem

Tahapan dalam proses perancangan sistem adalah sebagai berikut [9]:

1. Menentukan objek penelitian.

2. Studi Pustaka

pengumpulan dan pencarian teori-teori yang berhubungan dengan konsep yang diteliti.

3. Pengumpulan Data dan Informasi

Kualitas dari informasi yang diperoleh ditentukan oleh valid tidaknya data yang didapatkan. Oleh karena itu pengumpulan data haruslah dilakukan dengan secermat mungkin.

4. Analisa Sistem

Analisa terhadap sistem dilakukan untuk mengetahui proses yang telah berjalan pada tempat penelitian. Dengan mempelajari kelemahan-kelemahan pada sistem yang berjalan maka dapat di kembangkan suatu sistem baru [10].

5. Analisa Kebutuhan Sistem

Analisa kebutuhan sistem dilakukan untuk mengetahui apa saja yang dibutuhkan sistem untuk dapat berjalan. Tujuan dilakukannya analisa kebutuhan sistem yaitu untuk mengeidentifikasikan apa saja yang masih direvisi dari sistem tersebut dan menjadikan suatu sistem itu bisa dan dapat digunakan setelah dilakukan langkah-langkah perbaikan.

6. Perancangan Database

Perancangan database atau basis data merupakan bagian yang penting dalam suatu sistem informasi. Karena merupakan bagian yang penting, jadi basis data harus di desain sebaik mungkin untuk menjaga kemungkinan terjadi kerusakaan data ataupun terjadi data yang berulang.

7. Perancangan Interface

Perancangan Interface (antar muka) sangat dibutuhkan agar tampilan program menjadi lebih menarik, tentunya dengan menggunakan kombinasi warna dan penempatan menu - menu yang mudah, sehingga mempermudah user untuk menggunakan sistem ini.

\section{1) Tahap Analisa}

Pada sistem yang di usulkan dalam sistem informasi ini terdiri dari 2 aktor, yaitu admin adalah bidang TIK, pengguna adalah aparat kepolisian Polda Gorontalo. Kerangka yang diusulkan mencoba untuk mengatasi permasalahan yang dialami dalam eksplorasi, terutama untuk mempermudah menemukan wilayah dan data lain yang diidentifikasi dengan rumah pejabat Polda Gorontalo 
JSAI : Journal Scientific and Applied Informatics

Vol. 4, No. 3, November 2021, hal. 286 297

E-ISSN: 2614-3054; P-ISSN: 2614-3062, Terakreditasi Kemenristekdikti, Sinta 5

\section{2) Tahap Desain}

a) Usecase Diagram

Usecase diagram menggambarkan interaksi antara satu atau lebih aktor dengan sistem informasi yang akan dibuat

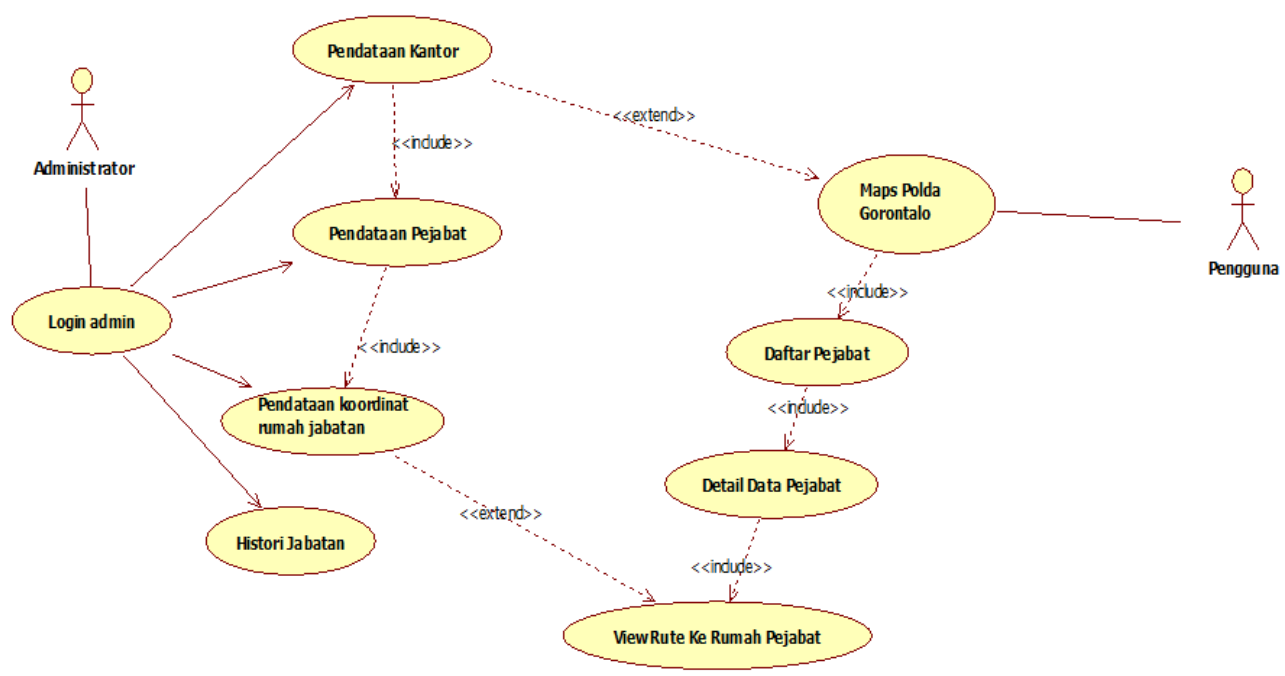

b) Activity Diagram

Gambar 2. Usecase yang Diusulkan

Activity diagram menggambarkan aliran kerja atau aktivitas dari sebuah sistem dan user

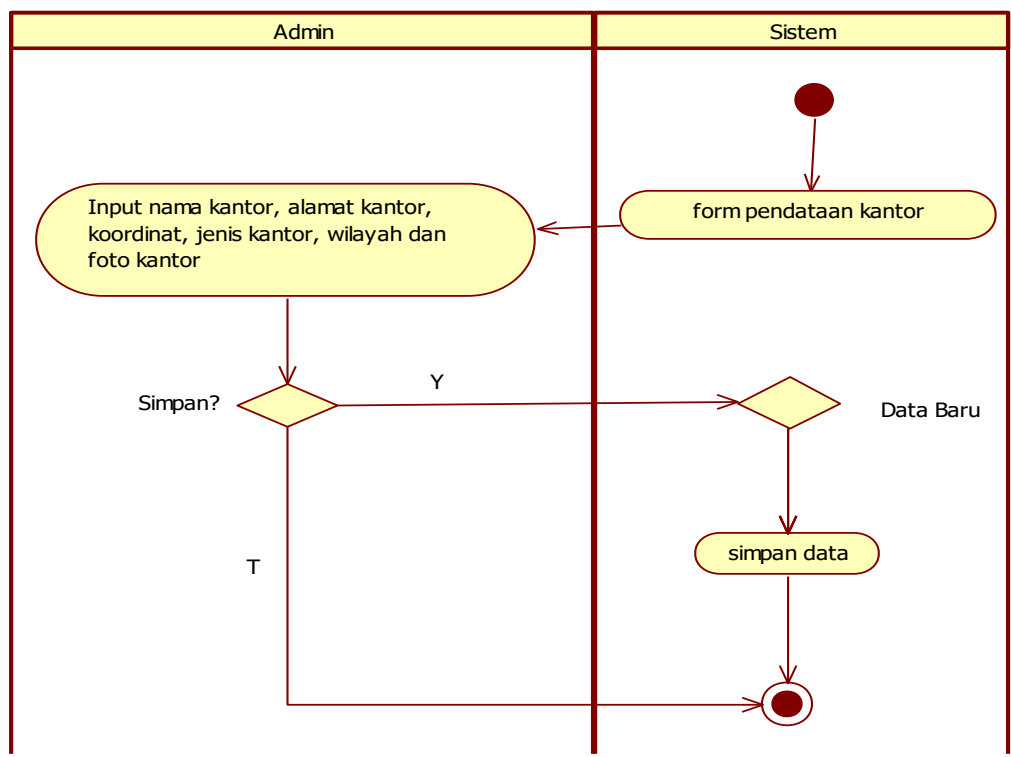

Gambar 3. Activity Diagram

c) Sequence Diagram 


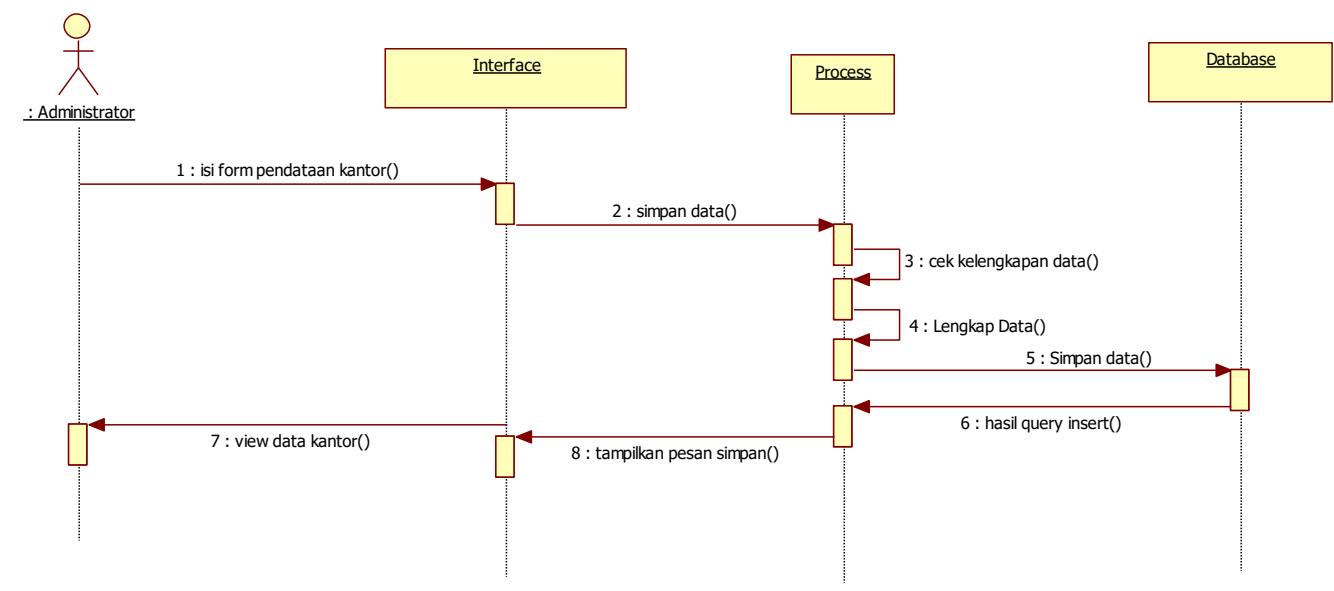

Gambar 4. Sequence Diagram

\section{d) Class Diagram}

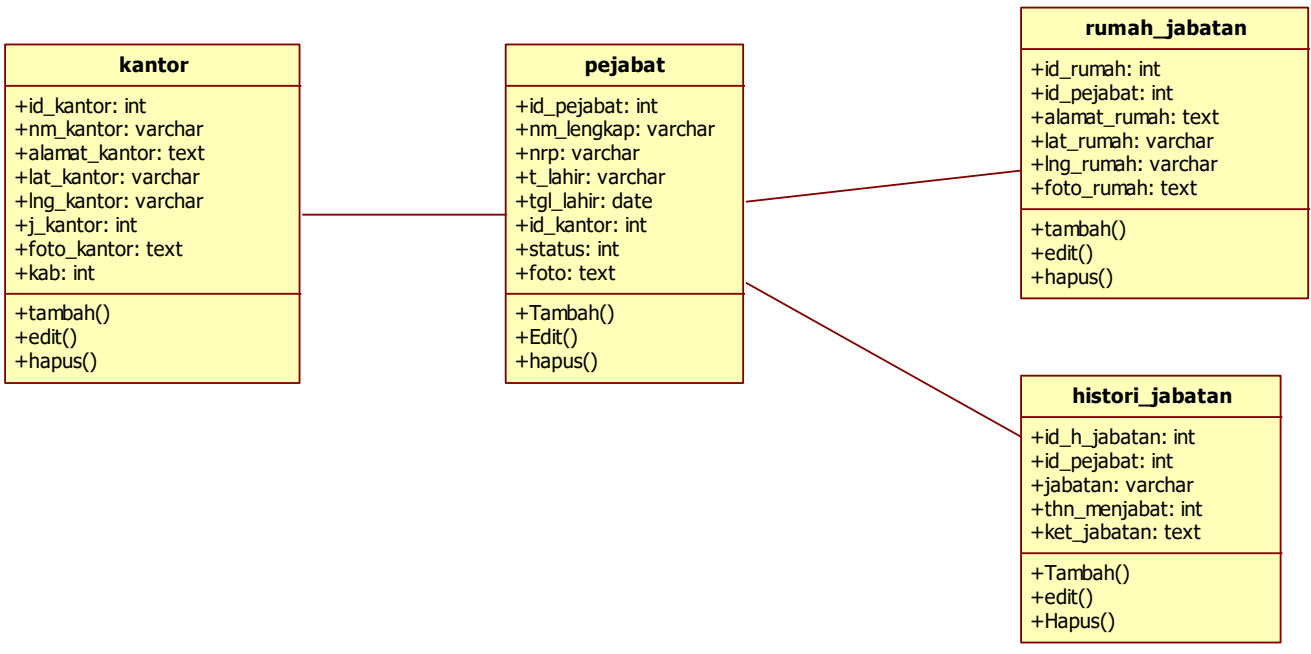

Gambar 5. Class Diagram

8. Perancangan Program

Perancangan program harus sesuai dengan perencanaan yang telah di teliti sebelumnya, dengan dasar sebuah analisis sistem, kemudian menerapkan sistem yang baru dengan bantuan use case, activity, dan sequence diagram dan mengimplementasikannya ke dalam bentuk aplikasi sistem [11].

\section{Pengujian Sistem}

Pengujian akan di lakukan menggunakan White Box dan Black Box. Pengujuian White Box merupakan pengujian algoritma pada sistem yang di bangun dengan menggunakan Flowchart dan Flowgraph. Sedangkan pengujian Black Box adalah pengujian penggunaan aplikasi sesuai yang di harapakan atau tidak [15].

\section{Implementasi}

Pada bagian ini,sistem informasi geografis berbasis android [16] yang dibuat setelah melalui tahapan pembangunan sebelumnya, akan diujikan pada Kepolisian Daerah (Polda) Gorontalo. Tahapan ini berfungsi memberi masukan melalui pengamatan tentang hal-hal apa yang perlu ditambahkan dalam sistem ini, diharapkan dengan mengetahui keinginan pengguna, sistem ini dapat lebih dikembangkan dan dapat lebih disempurnakan.

\section{HASIL DAN ANALISIS}

\subsection{Desain Graphic User Interface Client (Android)}


JSAI : Journal Scientific and Applied Informatics

Vol. 4, No. 3, November 2021, hal. 286 297

E-ISSN: 2614-3054; P-ISSN: 2614-3062, Terakreditasi Kemenristekdikti, Sinta 5

\section{Halaman Splash Screen}

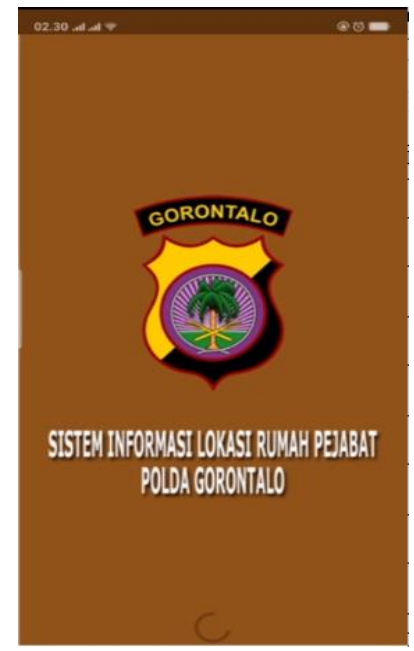

Gambar 6. Halaman Splash Screen

Tampilan di atas adalah tampilan halaman splash screen. Ketika klien menjalankan program, halaman akan dialihkan ke halaman layar tabur. Di halaman ini ada beberapa kapasitas termasuk memeriksa asosiasi yang digunakan dan membangun asosiasi dengan pekerja. Setelah taburan layar muncul, klien akan dikoordinasikan ke halaman peta kantor polisi.

\section{Halaman Maps Kantor Kepolisian}

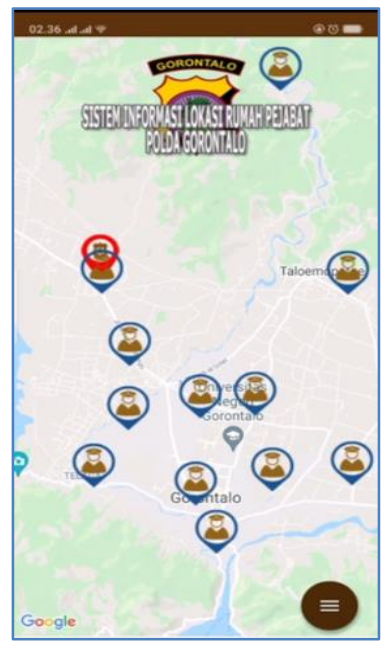

Gambar 7. Halaman Maps Kantor Kepolisian

Tampilan di atas adalah tampilan halaman maps kantor kepolisian. Pada halaman ini di tampilkan daftar kantor kepolisian dalam bentuk marker pada maps. Pada halaman ini tersedia filter data setiap kabupaten/kota dalam wilayah Provinsi Gorontalo.

\section{Halaman Filter Data Kota Gorontalo}




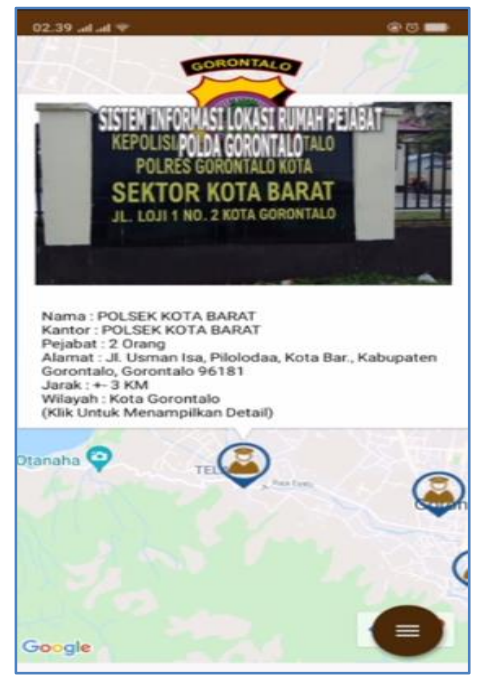

Gambar 8. Halaman Filter Data Kota Gorontalo

Gambar di atas adalah tampilan untuk halaman filter data Kota Gorontalo. Halaman ini setelah di pilih Kota Gorontalo pada pilihan menu pada bagian bawah halaman maps. Jendela info (InfoWindow) akan ditampilkan setelah salah satu ikon marker di tap.

\section{Halaman Daftar Pejabat Polri}

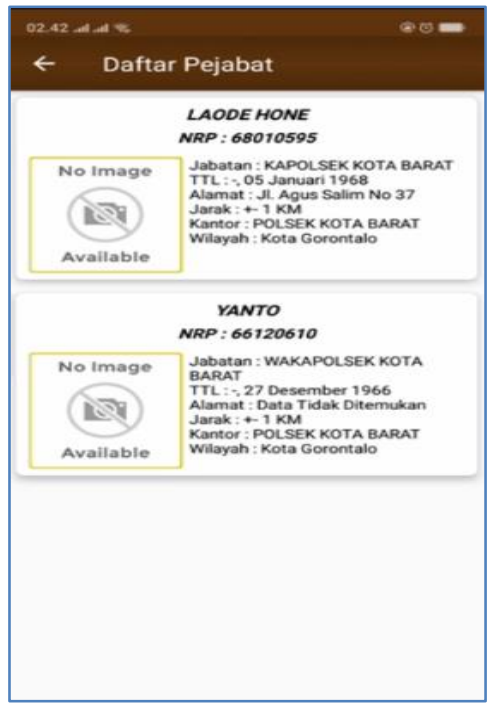

Gambar 9. Halaman Daftar Pejabat Polri

Gambar di atas adalah tampilan untuk daftar pejabat sesuai kantor terpilih pada halaman maps kantor kepolisan sebelumnya. 


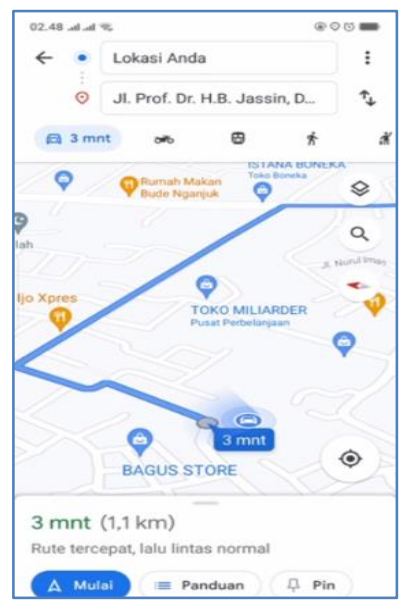

Gambar 10. Halaman Rute

Gambar di atas adalah tampilan untuk rute ke rumah pejabat sesuai pejabat terpilih pada halaman detail pejabat sebelumnya. Rute yang di tampilkan menggunakan fasilitas rute dari google maps.

\subsection{Hasil Pengujian}

Dalam pengujian sistem penulis menggunakan dua metode, yaitu white box dan black box :

\section{Whitebox}

Untuk pengujian white box, penelitian ini menggunakan modul pendataan kantor kepolisian yang dilakukan dari sisi website. Flowchart dan flowgraph untuk mengukur whitebox dapat dilihat pada gambar di bawah ini :

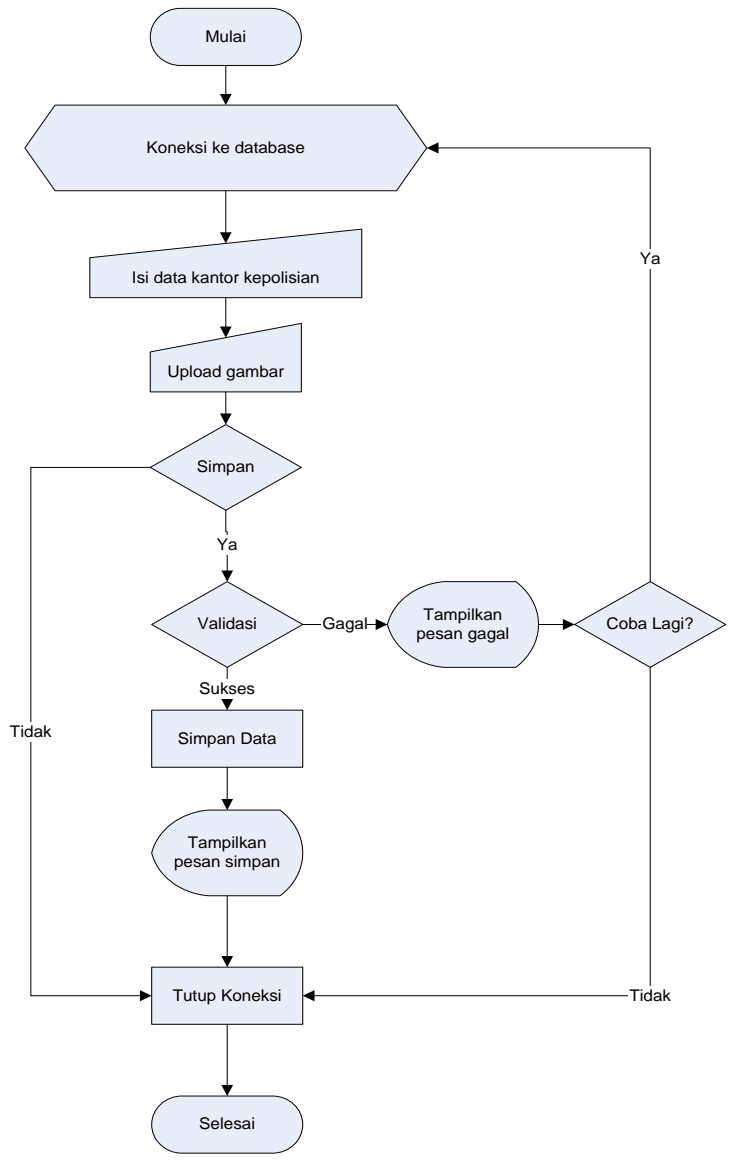

Gambar 11. Flowchart Modul Pengisian Data Kantor Kepolisian 


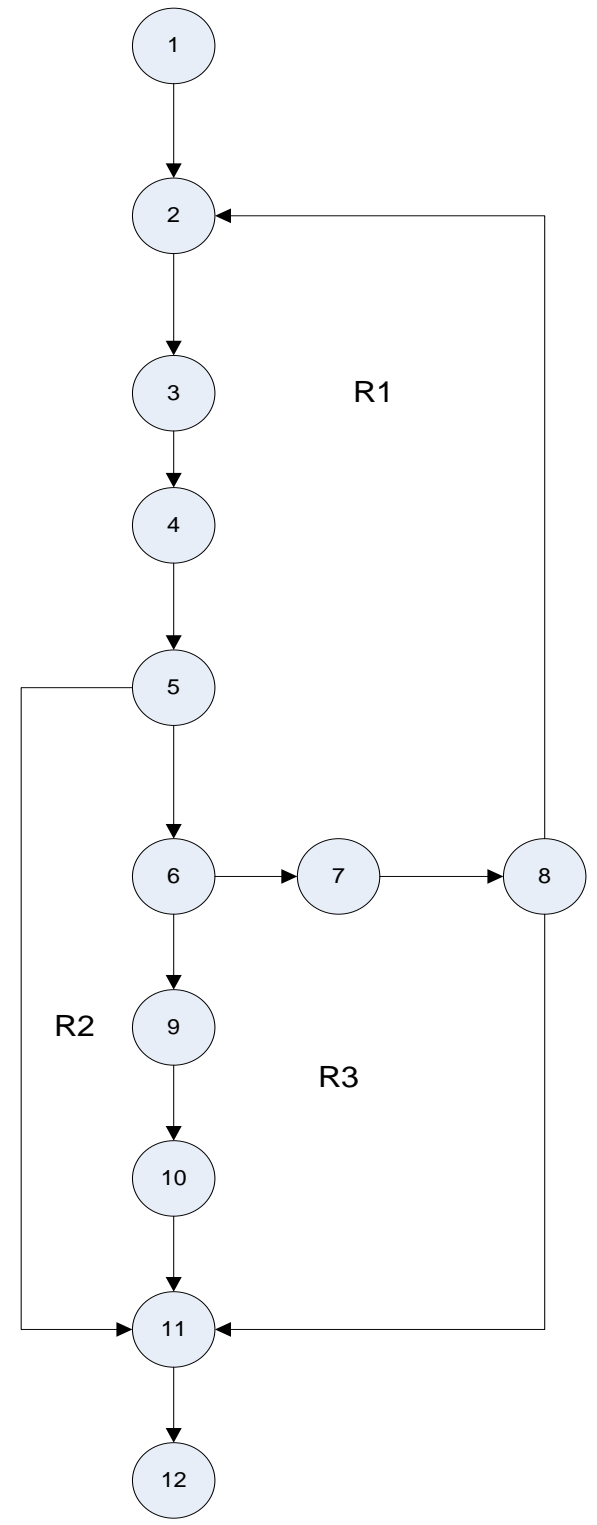

Gambar 12. Flowgraph

\section{Blackbox}

Pengujian blackbox fokus pada keperluan fungsional dari perangkat lunak. Maka dari itu ujicoba blackbox memungkinkan pengembang perangkat lunak untk membuat himpunan kondisi masukan yang bisa melatih seluruh syarat - syarat fungsional suatu sistem apakah berjalan sesuai yang diharapkan atau sebaliknya

Tabel 1. Pengujian Blackbox

\begin{tabular}{|c|c|c|c|c|}
\hline No & Input/Event & Proses & $\begin{array}{c}\text { Output/Next } \\
\text { State }\end{array}$ & $\begin{array}{c}\text { Hasil } \\
\text { Pengujian }\end{array}$ \\
\hline 1. & $\begin{array}{l}\text { Jika menu kota } \\
\text { gorontalo ditekan }\end{array}$ & $\begin{array}{l}\text { FloatingActionButton cKota }= \\
\text { (FloatingActionButton) } \\
\text { findViewById(R.id.kotagorontalo); } \\
\text { cKota.setOnClickListener(new } \\
\text { View.OnClickListener() \{ } \\
\quad \text { @Override } \\
\text { public void onClick(View view) \{ } \\
\quad \text { Info = "1"; } \\
\text { getJSON(); } \\
\} \\
\} \text { \}); }\end{array}$ & $\begin{array}{l}\text { Tampilkan kantor } \\
\text { kepolisian kota } \\
\text { gorontalo }\end{array}$ & Sesuai \\
\hline
\end{tabular}


JSAI : Journal Scientific and Applied Informatics

Vol. 4, No. 3, November 2021, hal. 286 297

E-ISSN: 2614-3054; P-ISSN: 2614-3062, Terakreditasi Kemenristekdikti, Sinta 5

\begin{tabular}{|c|c|c|c|c|}
\hline 3. & $\begin{array}{l}\text { Jika menu kab. } \\
\text { gorontalo di tekan }\end{array}$ & $\begin{array}{l}\text { FloatingActionButton cKabgor = } \\
\text { (FloatingActionButton) } \\
\text { findViewById(R.id.kabgorontalo); } \\
\text { cKabgor.setOnClickListener(new } \\
\text { View.OnClickListener() \{ } \\
\quad \text { @Override } \\
\text { public void onClick(View view) \{ } \\
\quad \text { Info = "2"; } \\
\quad \text { getJSON(); } \\
\} \\
\text { \}); }\end{array}$ & $\begin{array}{l}\text { Tampilkan kantor } \\
\text { kepolisian kab. } \\
\text { gorontalo }\end{array}$ & Sesuai \\
\hline 4. & $\begin{array}{l}\text { Jika menu } \\
\text { infoWindow di } \\
\text { peta di tekan }\end{array}$ & $\begin{array}{l}\text { public void onInfoWindowClick(Marker } \\
\text { marker) }\{ \\
\text { LatLng Tujuan = marker.getPosition(); } \\
\text { Tujuan1 = } \\
\text { String.valueOf(Tujuan.latitude); } \\
\text { Tujuan2 = } \\
\text { String.valueOf(Tujuan.longitude); } \\
\text { Intent } x=\text { new Intent(MapsActivity.this, } \\
\text { LihatPejabat.class); } \\
\text { x.putExtra(Config.KEY_LAT, Tujuan1); } \\
\text { x.putExtra(Config.KEY_LNG, Tujuan2); } \\
\text { startActivity(x); } \\
\text { \} }\end{array}$ & $\begin{array}{l}\text { Tampilkan } \\
\text { halaman daftar } \\
\text { pejabat sesuai } \\
\text { kantor terpilih }\end{array}$ & Sesuai \\
\hline 4. & $\begin{array}{l}\text { Jika menu about } \\
\text { aplikasi ditekan }\end{array}$ & $\begin{array}{l}\text { FloatingActionButton AboutAplikasi = } \\
\text { (FloatingActionButton) } \\
\text { findViewById(R.id.tabout); } \\
\text { AboutAplikasi.setOnClickListener(new } \\
\text { View.OnClickListener() \{ } \\
\quad \text { @ Override } \\
\text { public void onClick(View view) \{ } \\
\quad \text { Intent intent = new } \\
\text { Intent(MapsActivity.this, } \\
\text { ActivityAbout.class); } \\
\quad \text { startActivity(intent); } \\
\} \quad \\
\}) ;\end{array}$ & $\begin{array}{l}\text { Tampil halaman } \\
\text { about aplikasi }\end{array}$ & Sesuai \\
\hline
\end{tabular}

\section{Implementasi}

Sistem yang dirancang selanjutnya akan diimplementasikan pada Kepolisian Daerah (Polda) Gorontalo. Untuk aplikasi sisi server akan langsung di pasang pada Bidang TIK Polda Gorontalo dan akan dioperasikan oleh petugas yang ada, selanjutnya untuk aplikasi mobile akan di upload ke playstore untuk dapat di download oleh masyarakat secara gratis.

\section{KESIMPULAN}

Berdasarkan hasil penelitian yang dilakukan oleh peniliti maka dapat diambil kesimpulan bahwa dengan ada nya aplikasi sistem informasi geografis yang berbasis android dapat memudahkan aparat kepolisian untuk dapat mencari lokasi pejabat Polda Gorontalo dan dapat memberikan informasi daftar pejabat serta histori jabatan pejabat Polda Gorontalo. 
[1] C. Denny, Desain dan Aplikasi GIS, Geographic Information System, Jakarta: PT. Gramedia, 2012

[2] S. Nugraha, "Hubungan Antara Kepolisian Dan Pemerintah Daerah Dalam Menegakkan Ketertiban Masyarakat," Jurnal Morality, vol. 4 Nomor 1, 2018..

[3] K. T. P. Gorontalo, Interviewee, Tentang POLDA Gorontalo. [Interview]. Januari 2021

[4] S. N. M. Rahman, "Sistem Informasi Geografis Pariwisata Kota Yogyakarta Berbasis Mobile Android," STMIK Amikom, Yogyakarta, 2012

[5] E. Prahasta, Sistem Informasi GeografisTutorial Arcview, Bandung: Informatika, 2010.

[6] adhyaksa, "Definisi Rumah Sebagai Sebuah Bangunan untuk Tempat Tinggal," https://www.adhyaksapersada.co.id, [Online]. $\quad$ Available: https://www.adhyaksapersada.co.id/pengertian-rumah/. [Accessed 23 April 2021]..

[7] N. S. H, Aplikasi Berbasis Android, Indonesia: Informatika Cetakan, 2015

[8] N. Safaat, Pemrograman Aplikasi Mobile Smarphone dan Table PC Bebasis Android, Bandung: Informatika, 2012.

[9] Y. Supriadi, Semua Bisa Menjadi Programer Android, vol. II, Jakarta: PT. Elex KompuIndo, 2014, p. 21.

[10] A. D. Kasman, Kolaborasi Dahsyat Android Dengan PHP \& MySQL, Yogyakarta: Lokomedia, 2003

[11] R. Hakim and Sutarto, Mastering Java : Konsep Pemrograman Java dan Penerapannya untuk membuat Software Aplikasi, Jakarta: PT. Elex Media Komputindo, 2010

[12] S. Dharwiyanti, "Pengantar Unified Modeling Language (UML)," 2003

[13] Sugiono, Metode Penelitian Kualitatif, Kuantitatif, dan R\&D, Bandung: Alfabeta, 2011

[14] A. B. B. Ladjamudin, Rekayasa Perangkat Lunak, Yogyakarta: Graha Ilmu, 2006

[15] A. Rosa dan M. Shalahuddin, Rekayasa Perangkat Lunak, Bandung: Informatika Bandung, 2013.

[16] Jan Nealbert, Pamela Anne, Romel Conde, " Ubiquitous Learning Environment Using Android Mobile Application, IMPACT:International Journal Of Research In Engineering \& Technology, ISSN(E):2321-8843;ISSN(P):2347-4599. Vol.2 Issue 2 Februari, 2014. 